\title{
Effects of Crop Load on Fruiting and Gas-exchange Characteristics of 'Braeburn'/M.26 Apple Trees at Full Canopy
}

\author{
Jens N. Wünsche ${ }^{1}$ and John W. Palmer \\ HortResearch, Nelson Research Centre, P.O. Box 220, RD 3 Motueka, New Zealand \\ Dennis H. Greer \\ HortResearch, Batchelor Research Centre, Private Bag 11 030, Palmerston North, New Zealand
}

\begin{abstract}
AdDitional IndEX words. fruit quality, leaf photosynthesis, leaf chlorophyll fluorescence, Malus sylvestris var. domestica, whole-canopy gas exchange, yield

Abstract. Effect of crop load on tree growth, leaf characteristics, photosynthesis, and fruit quality of 5-year-old 'Braeburn' apple [Malus sylvestris (L.) Mill. var. domestica (Borkh.) Mansf.] trees on Malling 26 (M.26) rootstock was examined during the 1994-95 growing season. Crop loads ranged from 0 to $57 \mathrm{~kg} /$ tree $\left[0\right.$ to $1.6 \mathrm{~kg}$ fruit $/ \mathrm{cm}^{2}$ trunk cross sectional area (TCA) or 0 to 8.7 fruit/cm² TCA]. Fruit maturity as indicated by background color, starch/iodine score, and soluble solids was advanced significantly on low-cropping trees compared to high-cropping trees. Whole-canopy leaf area and percentage tree light interception increased linearly with a significant trend as crop load decreased. From midseason until fruit harvest, leaf photosynthesis decreased significantly on lighter cropping trees and similarly, a positive linear trend was found between whole-canopy gas exchange per unit area of leaf and crop load. Leaf starch concentration in midseason increased linearly as crop load decreased, providing some explanation for the increased down-regulation of photosynthesis on trees with lower crop loads. After fruit harvest, the previous crop loads had no effect on leaf photosynthesis and preharvest differences in whole-canopy gas exchange per unit area of leaf were less pronounced. At each measurement date, daily whole-canopy net carbon exchange and transpiration closely followed the diurnal pattern of incident photosynthetic photon flux. The photochemical yield and electron transport capacity depended on crop load. This was due mostly to reaction center closure before harvest and an increased nonphotochemical quenching after harvest.
\end{abstract}

Previous studies investigating the effect of fruit on photosynthesis, partitioning of assimilates, and dry matter accumulation have shown higher leaf photosynthetic efficiencies in fruiting than in nonfruiting apple (Malus sylvestris var. domestica) trees (e.g., Avery, 1975; Hansen, 1970; Heim et al., 1979; Lenz, 1986; Maggs, 1963). Palmer (1986, 1992) extended the fruiting and nonfruiting approach by attempting to determine the shape of the photosynthetic response curve to a range of apple crop loads, but was unable to clearly define the relationship. Under prevailing climatic conditions of New Zealand, Palmer et al. (1997) found that leaf assimilation rate was positively and curvilinearly related to crop load.

Although several research groups have monitored gas exchange of whole canopies, only Wibbe et al. (1993) attempted to examine the effect of fruiting versus nonfruiting on the carbon budget of apple tree canopies. They provided an integrated approach toward understanding whole-tree carbon balance. However, to develop accurate photosynthesis response curves, which would be useful in modelling whole-tree carbon balance, inclusion of various crop loads is essential. Our work provides data on a range of crop loads.

Measurement of chlorophyll fluorescence in situ is a relatively new technique for assessing the underlying photochemistry of horticultural plants grown in orchard conditions (Greer, 1995). In particular, this technique allows an assessment of the orderly

Received for publication 19 Jan. 1999. Accepted for publication 1 Oct. 1999. This research was funded by the New Zealand Foundation for Research, Science and Technology. Use of trade names does not imply endorsement of the products named nor criticism of similar ones not named. The cost of publishing this paper was defrayed in part by the payment of page charges. Under postal regulations, this paper therefore must be hereby marked advertisement solely to indicate this fact.

${ }^{1}$ To whom reprint requests should be addressed; e-mail jwunsche@hort.cri.nz. dissipation of absorbed light energy through the photochemical pathway to photosynthesis or through the xanthophyll-cyclemediated photoprotective pathway (Demmig-Adams and Adams, 1996) and measured as nonphotochemical quenching (Osmond, 1994). Many studies have focused on environmental stress conditions that affect photosynthesis (e.g., Chow, 1994). On the other hand, there is little research on the underlying physiology of photosynthesis as affected by internal stresses such as accumulation of carbohydrate through changes in source-sink relations of plants. However, Buwalda and Noga (1994) have demonstrated that both photochemical and nonphotochemical quenching varied between fruiting and nonfruiting apple trees. Again, our intention was to examine these characteristics in relation to a range of crop loads.

\section{Materials and Methods}

Plant material and experimental design. Effect of crop load on whole-canopy leaf area, tree light interception, leaf and whole-canopy gas-exchange characteristics, and fruit quality of 5-year-old 'Braeburn' apple trees, grown on dwarfing M.26 rootstock, was examined at the Nelson Research Centre, New Zealand, during the middle to late part of the 1994-95 growing season. Trees were planted at a spacing of $5 \times 2.5 \mathrm{~m}$ in north-south oriented rows and trained as slender spindles. Sixteen trees were assigned in a randomized complete block design to four blocks of four crop load treatments. At full bloom (7 Oct. 1994), the trees were thinned to give a high, medium, low, and no crop load. The cropping levels were established by removing different numbers of entire spur and terminal extension shoot flower clusters: 1) no clusters removed, 2) two in three clusters removed, 3) five in six clusters removed, and 4) all clusters removed and by reducing all 
remaining spur and terminal clusters to two flowers. In addition, all lateral flowers on 1-year-old wood were removed. Spurs refer to the short shoot complex that typically bears the flower cluster, fruit and lateral bourse shoot. Extension shoots refer to long vegetative first year shoots.

LEAF AREA AND TREE LIGHT INTERCEPTION. Whole-canopy leaf area was assessed as described previously by Wünsche and Palmer (1998). At full canopy, the total number of spurs $(<5 \mathrm{~cm}$ in length) and current year's extension shoots ( $>5 \mathrm{~cm}$ in length) were counted on each tree. Individual leaf areas of all unfolded leaves on randomly selected 5 spurs and 10 extension shoots per tree were measured nondestructively using the transparent grid of Freeman and Bolas (1956). Total leaf area of the whole canopy was estimated from the sum of the products of the total spur and shoot number by their respective mean leaf areas.

Percentage tree light interception at full canopy was calculated from records of above-canopy incident irradiance and of tree light transmission, measured in a defined grid pattern below canopy (Wünsche et al., 1995) using selenium cells (Palmer, 1987). The voltage output from the sensors was recorded over the course of a whole day on a datalogger (Delta logger, Delta-T Devices Ltd., Cambridge, United Kingdom).

LEAF PHOTOSYNTHESIS. Light saturated leaf photosynthesis measurements were recorded with a LCA-3 system using a Parkinson leaf chamber (ADC, Hoddesdon, United Kingdom) on sunny days when irradiance on the outside of the chamber was in excess of 1200 $\mu \mathrm{mol} \cdot \mathrm{m}^{-2} \cdot \mathrm{s}^{-1}$. Randomly selected fully mature bourse shoot leaves were measured in the morning and afternoon $\approx 2$ to $3 \mathrm{~h}$ before and 2 to $3 \mathrm{~h}$ after midday at each sampling time, respectively.

LEAF CHLOROPHYLL FLUORESCENCE. Leaf chlorophyll fluorescence was measured using a pulse modulated fluorometer (PAM2000, Walz, Effeltrich, Germany). For each block of trees, two detached leaf discs $\left(25 \mathrm{~mm}^{2}\right)$ per treatment were dark adapted in cuvettes for at least $15 \mathrm{~min}$ before minimal $\left(\mathrm{F}_{\mathrm{o}}\right)$ and maximal $\left(\mathrm{F}_{\mathrm{m}}\right)$ fluorescence being measured as described by Greer (1995). For the subsequent in situ quenching analysis, the highest $\mathrm{F}_{\mathrm{m}}$ value was selected. Maximal fluorescence yield $\left(\mathrm{F}_{\mathrm{m}}{ }^{\prime}\right)$ was then measured concurrently with the photosynthetic photon flux $(P P F)$ on

Table 1. Effect of crop load on yield per tree, fruit number per tree, mean fruit weight, whole-canopy leaf area, and tree light interception of 5-yearold 'Braeburn'/M.26 apple trees. All quadratic effects were nonsignificant. Yield per trunk cross-sectional area (TCA) was 1.6, 1.0, 0.52, and $0 \mathrm{~kg} \cdot \mathrm{cm}^{-2}$ and fruit number per TCA was $8.7,3.3,1.5$, and $0 / \mathrm{cm}^{2}$ for high, medium, low, and no crop load, respectively.

\begin{tabular}{|c|c|c|c|c|c|}
\hline $\begin{array}{l}\text { Crop } \\
\text { load }\end{array}$ & $\begin{array}{c}\text { Yield } \\
\text { (kg/tree) }\end{array}$ & $\begin{array}{c}\text { Fruit } \\
\text { (no./tree) }\end{array}$ & $\begin{array}{l}\text { Mean } \\
\text { fruit } \\
\text { wt }(\mathrm{g})\end{array}$ & $\begin{array}{l}\text { Leaf } \\
\text { area } \\
\left(\mathrm{m}^{2}\right) \\
\end{array}$ & $\begin{array}{c}\text { Light } \\
\text { interception } \\
(\%)\end{array}$ \\
\hline High & 57.3 & 306 & 187 & 10.7 & 27.7 \\
\hline Medium & 35.1 & 117 & 300 & 14.0 & 32.1 \\
\hline Low & 18.2 & 52 & 345 & 15.7 & 35.0 \\
\hline None & 0.0 & 0 & - & 17.9 & 37.4 \\
\hline $\operatorname{LSD}_{(0.05)}$ & 8.7 & 39.2 & 19.5 & 5.3 & 8.8 \\
\hline Linear trend & $* * *$ & $* * *$ & $* * *$ & $* * *$ & $*$ \\
\hline
\end{tabular}

Significant at $P \leq 0.05$ or 0.001 , respectively.

Table 2. Effect of crop load on various fruit quality parameters of 5-year-old 'Braeburn'/M.26 apples at harvest. All quadratic effects were nonsignificant.

\begin{tabular}{|c|c|c|c|c|c|}
\hline $\begin{array}{l}\text { Crop } \\
\text { load }\end{array}$ & $\begin{array}{l}\text { Background } \\
\text { color }(\text { score })^{z}\end{array}$ & $\begin{array}{c}\text { Soluble } \\
\text { solids (\%) }\end{array}$ & $\begin{array}{l}\text { Starch-iodine } \\
\text { (score) }\end{array}$ & $\begin{array}{l}\text { Firmness } \\
\quad(\mathrm{kg})\end{array}$ & $\begin{array}{c}\text { Dry matter } \\
(\%)\end{array}$ \\
\hline$\overline{\text { High }}$ & 4.6 & 11.6 & 1.7 & 8.4 & 14.3 \\
\hline Medium & 6.2 & 13.3 & 2.8 & 9.5 & 16.6 \\
\hline Low & 6.7 & 14.3 & 3.3 & 10.0 & 17.8 \\
\hline $\operatorname{LSD}_{(0.05)}$ & 1.8 & 2.0 & 1.8 & 1.4 & 2.4 \\
\hline Linear trend & $* * *$ & $* * *$ & $* * *$ & $* * *$ & $* * *$ \\
\hline
\end{tabular}

${ }^{\mathrm{z}} \mathrm{A}$ higher score indicates a more yellow background color.

${ }^{* * * *}$ Significant at $P \leq 0.001$.

Table 3. Effect of crop load on leaf photosynthesis rate $\left(\mu \mathrm{mol} \cdot \mathrm{m}^{-2} \cdot \mathrm{s}^{-1}\right)$ at $\approx 2$ to $3 \mathrm{~h}$ before and after solar noon of 5-year-old 'Braeburn'/M.26 apple trees. Harvest was $181 \mathrm{~d}$ after full bloom (DAFB). All quadratic effects were nonsignificant.

\begin{tabular}{|c|c|c|c|c|c|c|c|}
\hline \multirow{3}{*}{$\begin{array}{l}\text { Crop } \\
\text { load }\end{array}$} & \multicolumn{7}{|c|}{ DAFB } \\
\hline & \multicolumn{2}{|c|}{97} & \multicolumn{2}{|c|}{149} & \multicolumn{2}{|c|}{201} & \multirow{2}{*}{$\frac{229}{12: 00 \mathrm{PM}}$} \\
\hline & $\mathrm{AM}$ & PM & $\mathrm{AM}$ & PM & $\mathrm{AM}$ & PM & \\
\hline$\overline{\text { High }}$ & 13.8 & 11.1 & 12.5 & 11.9 & 11.1 & 10.2 & 6.1 \\
\hline Medium & 10.9 & 9.0 & 11.9 & 11.1 & 10.9 & 11.2 & 6.5 \\
\hline Low & 7.2 & 4.9 & 9.8 & 9.8 & 10.8 & 9.4 & 7.6 \\
\hline None & 5.3 & 3.2 & 7.4 & 7.3 & 10.6 & 10.0 & 6.4 \\
\hline $\operatorname{LSD}_{(0.05)}$ & 2.3 & 1.2 & 1.4 & 1.8 & 1.4 & 2.6 & 4.0 \\
\hline Linear trend & $* * *$ & $* * *$ & $* * *$ & $* * *$ & NS & NS & NS \\
\hline
\end{tabular}

$\overline{\mathrm{NS}, * * * *}$ Nonsignificant or significant at $P \leq 0.001$, respectively. 
five randomly selected bourse shoot leaves on each treatment tree. After each reading, the leaf was darkened transiently and minimal fluorescence $\left(\mathrm{F}_{\mathrm{o}}{ }^{\prime}\right)$ was measured after a $5 \mathrm{~s}$ exposure to far-red light. The fluorescence yield $\left(\Delta \mathrm{F} / \mathrm{F}_{\mathrm{m}}\right)$, photochemical quenching coefficient $\left(\mathrm{q}_{\mathrm{p}}\right)$, and the nonphotochemical quenching coefficient (NPQ) were determined for each leaf according to the procedure of Van Kooten and Smel (1990).

WHOLE-CANOPY CARBON AND WATER VAPOR FLUXES. An automatic monitoring and control gas-exchange system, as described by Wünsche and Palmer (1997), was used to measure wholecanopy net carbon exchange (NCE) and whole-canopy transpiration. Use of four transparent through-flow canopy cuvettes allowed simultaneous recording of carbon and water vapor fluxes of one tree from each treatment over a 2 -week period at each sampling time.

LEAF STARCH. In midseason, 10 leaf discs (15 mm diameter) were collected from each tree within a treatment at midday under sunny conditions. Samples were frozen immediately on dry ice and then freeze dried. For analysis, leaf samples were ground using a ring grinder. A subsample of $0.1 \mathrm{~g}$ was extracted in $20 \mathrm{~mL}$ $80 \%$ ethanol at $60{ }^{\circ} \mathrm{C}$ for $1 \mathrm{~h}$ and then filtered. The insoluble residue was analyzed for starch spectrophotometrically (Smith et al., 1992).

YIELD AND FRUIT QUALITY. Fruit number and fruit weight were recorded for each tree at harvest on 7 Apr. 1995 [181 d after full bloom (DAFB)]. Twenty apples per tree were randomly sampled for measurements of: individual fruit weight, background color (background color scale from 1 to 8 , green to yellow), soluble solids (Atago N-20 hand-held refractometer, Atago Co. Ltd., Tokyo, Japan $)$, starch-iodine score $(0=$ all tissues stained black to $7=$ no staining), fruit firmness (fruit pressure tester, model FT 327, 11.3-mm-diameter screwhead, Istituto di Coltivazioni Arboree, University of Milan, Italy) and dry matter content.

Statistical Analysis. Analysis of variance was used to evaluate the effect of crop load on whole-canopy leaf area and light interception, leaf photosynthesis, leaf chlorophyll fluorescence, yield, and fruit quality at harvest. The main effect of crop load was analyzed for linear and quadratic trends. Regression analysis was used to evaluate the relationships between leaf photosynthesis and leaf stomatal conductance, leaf photosynthesis and photochemical yield and whole-canopy net carbon exchange and crop load. Data were analyzed using Genstat (Rothamsted, United Kingdom) and displayed graphically using Origin.

\section{Results}

The four flower thinning treatments produced a wide range of crop loads, resulting in significant differences in yield per tree in spite of trees with reduced fruit numbers per tree having higher mean fruit weights (Table 1). Percentage tree light interception at full canopy increased significantly with lighter cropping trees (Table 1). This trend was caused by changes in whole-canopy leaf area, with a significant increase of leaf area with lower crop loads.

Compared to the high-cropping trees, fruit of lighter cropping trees were significantly more mature at harvest as indicated by background color, starch/iodine score and soluble solids (Table 2). Fruit firmness and dry matter increased linearly with decreasing crop load.

Preharvest leaf photosynthesis was correlated linearly to crop load with $\approx 65 \%$ and $40 \%$ lower rates recorded in the noncropping trees at 97 and 149 DAFB, respectively (Table 3). From 97 to 201 DAFB, leaf photosynthesis showed little change on the high- and medium-cropping trees but increased substantially on trees with low and no crop load; thus, there were no differences between the treatments at 201 DAFB. Leaf photosynthesis was generally higher in the morning than in the afternoon, with an average of $25 \%$ higher rates at 97 DAFB and 5\% higher rates at 149 and 201 DAFB. At 229 DAFB, $\approx 6$ weeks after fruit harvest, midday leaf photosynthesis was similar in all crop load treatments with rates on average $37 \%$ lower than at 201 DAFB. Stomatal conductance accounted for $\approx 80 \%$ of the variance of leaf photosynthesis (Fig. 1).

At 109 DAFB, after completion of leaf area development and shoot growth, gas exchange on both a whole-canopy and per unit area of leaf basis were higher on the high-cropping tree, while only small differences were found among trees with reduced crop loads (Table 4; Fig. 2). At 165 DAFB, 2 weeks before fruit harvest, wholecanopy gas exchange was markedly lower on the noncropping tree compared to the fruiting trees among which differences were small (Table 4). Whole-canopy gas exchange per unit area of leaf, however, decreased substantially with lighter cropping trees (Table 4; Fig. 3). At 211 DAFB, 1 month after fruit harvest, whole-canopy gas exchange increased slightly with reduced crop load, while differences in whole-canopy gas exchange per unit area of leaf was less pronounced among the various crop load treatments (Table 4; Fig. 4). Figure 5 presents the relationship between crop load and mean whole-canopy NCE per unit area of leaf at each measurement time and shows a positively linear response that accounted for $\approx 70 \%$ of the variance.

The effect of crop load on both daytime NCE and nighttime dark respiration per unit area of leaf was similar, indicating that canopies with high net carbon uptake during the photoperiod had proportionally more carbon loss during the night period (Table 4). Compared to preharvest records, the largely reduced dark respiration rates on the fruiting trees at 211 DAFB were due likely to the exclusion of fruit respiration and the relatively low night temperature. At each measurement date, diurnal patterns of whole-canopy NCE and transpiration followed closely the daily course of total incident $P P F$, indicating that canopy gas exchange was affected largely by total canopy light interception (Figs. 2, 3, and 4).

In midseason, at 135 DAFB, leaf starch concentration was linearly and negatively related to crop load (Table 5). Although leaf mass per unit of leaf area (MLA) increased by $2.2 \mathrm{mg} \cdot \mathrm{cm}^{-2}$, starch per unit leaf area increased by only $0.8 \mathrm{mg} \cdot \mathrm{cm}^{-2}$, indicating

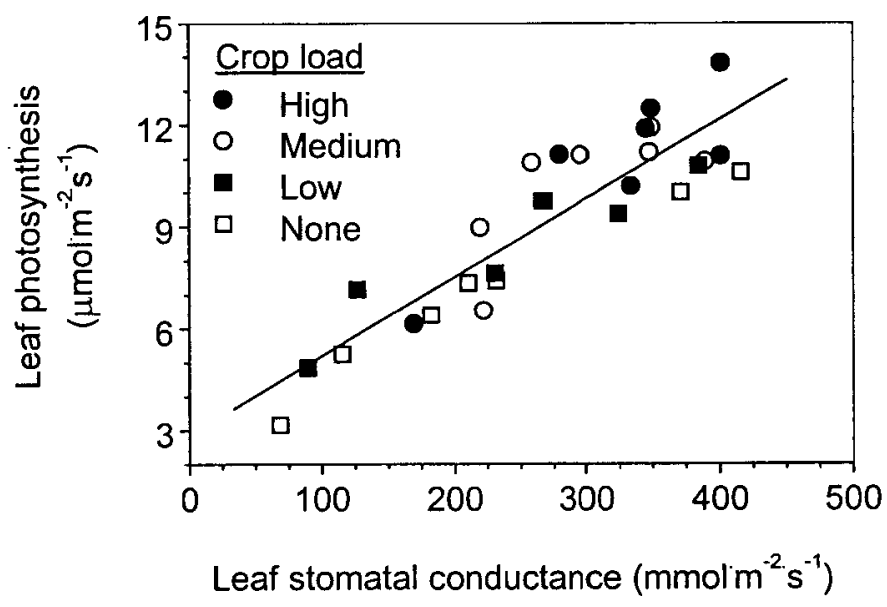

Fig. 1. Relationship between leaf photosynthesis (A) and stomatal conductance $\left(\mathrm{g}_{\mathrm{s}}\right)$ of bourse shoot leaves of 5-year-old 'Braeburn'/M.26 apple trees with none, low, medium, and high crop load. Data represent means of each measurement time. Linear regression equation $(\mathrm{n}=28)$ is $\mathrm{A}=0.023 \mathrm{~g}_{\mathrm{s}}+2.9, r^{2}=0.80$. 
Table 4. Effect of crop load on mean gas exchange on a whole-canopy (per tree) and unit area of leaf (per $\mathrm{m}^{2}$ ) basis over a 2-week period at each measurement time of 5-year-old 'Braeburn'/M.26 apple trees. Day/night length were 13/11, 11/13, and 10/14 h; and maximum day/minimum night temperatures were $22.5 / 17.5,21 / 15$, and $16 / 8{ }^{\circ} \mathrm{C}$ at 109,165 , and $211 \mathrm{~d}$ after full bloom (DAFB), respectively. Estimated whole-canopy leaf area was 10.0, 13.4, 16.1, and $18.8 \mathrm{~m}^{2}$ and percentage tree light interception was $29.4,33.5,36.6$, and $38.2 \%$ for the high-, medium-, low, and noncropping tree, respectively. Harvest was 181 DAFB.

\begin{tabular}{|c|c|c|c|c|c|c|}
\hline \multirow[b]{2}{*}{ Crop } & \multicolumn{6}{|c|}{ DAFB } \\
\hline & 109 & 165 & 211 & 109 & 165 & 211 \\
\hline load & \multicolumn{3}{|c|}{ Whole-canopy basis } & \multicolumn{3}{|c|}{ Leaf area basis } \\
\hline
\end{tabular}

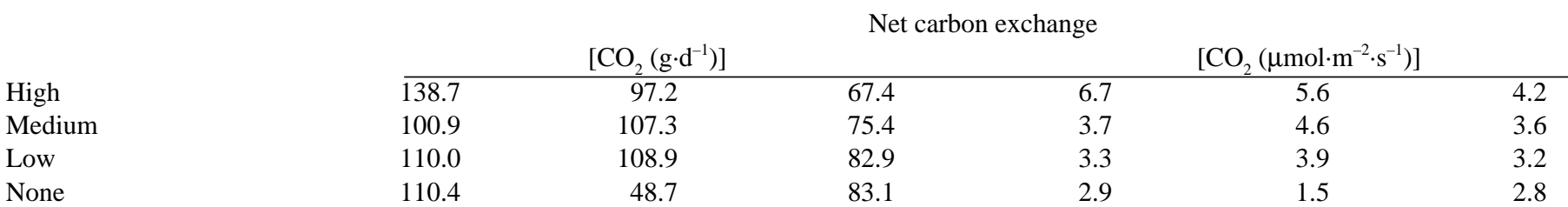

\begin{tabular}{lcccccc} 
& \multicolumn{3}{c}{ Dark respiration } & & \multicolumn{2}{c}{$\left[\mathrm{CO}_{2}\left(\mu \mathrm{mol} \cdot \mathrm{m}^{-2} \cdot \mathrm{s}^{-1}\right)\right]$} \\
\cline { 3 - 7 } High & 7.7 & 7.0 & 3.4 & 0.44 & 0.34 & 0.15 \\
Medium & 5.9 & 8.7 & 3.8 & 0.25 & 0.32 & 0.13 \\
Low & 6.9 & 5.1 & 2.9 & 0.24 & 0.15 & 0.08 \\
None & 2.4 & 3.7 & 3.9 & 0.07 & 0.09 & 0.09
\end{tabular}

\begin{tabular}{|c|c|c|c|c|c|c|}
\hline & & & & & & \\
\hline & & $\mathrm{O}(\mathrm{kg}$ & & & $\mathrm{amol} \cdot \mathrm{m}$ & \\
\hline High & 11.9 & 9.6 & 5.6 & 0.76 & 0.62 & 0.36 \\
\hline Medium & 8.1 & 9.4 & 6.0 & 0.39 & 0.45 & 0.29 \\
\hline Low & 8.2 & 10.4 & 7.0 & 0.33 & 0.41 & 0.28 \\
\hline ne & 8.7 & 7.7 & 7.9 & 0.30 & 0.26 & 0.27 \\
\hline
\end{tabular}

that, besides starch, other products must have been accumulating in the leaves.

Treatment differences in photochemical yield $\left(\Delta \mathrm{F} / \mathrm{F}_{\mathrm{m}}{ }^{\prime}\right)$ and electron transport capacity (ETR) were most apparent in midseason at 97 DAFB. At this growth stage they were both significantly $(P$ $<0.001)$ dependent on crop load, with the noncropping trees
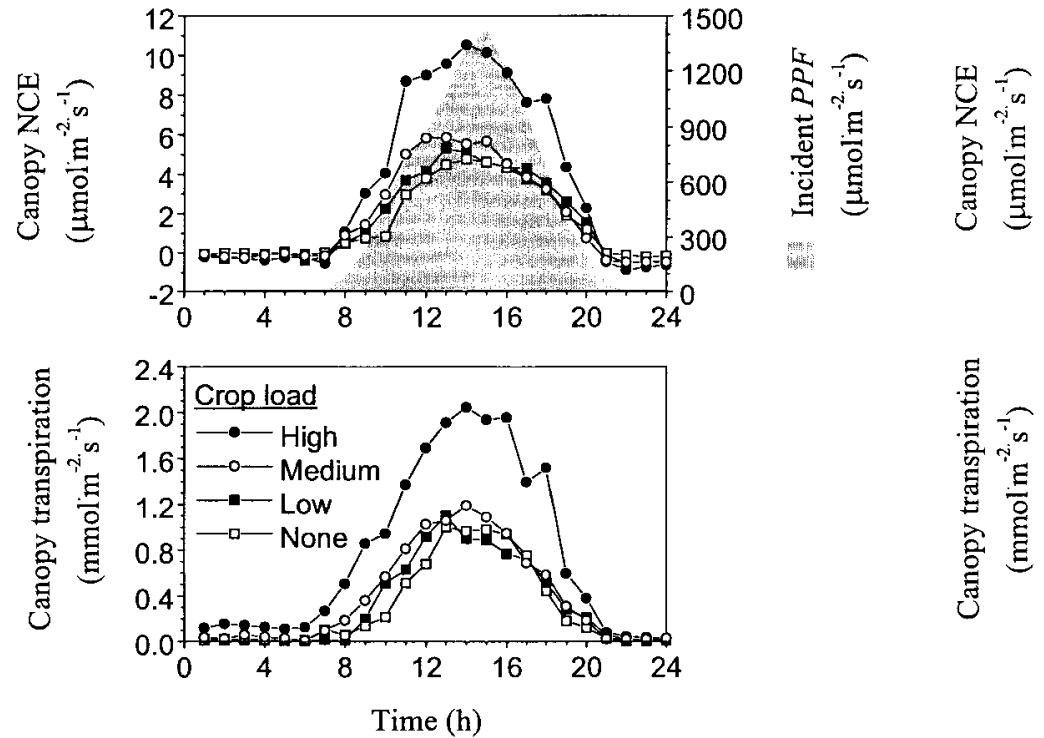

Fig. 2. Diurnal changes of whole-canopy net carbon exchange (NCE) and transpiration per unit area of leaf over a 2 -week period [ $\approx 109 \mathrm{~d}$ after full bloom (DAFB)] of 5-year-old 'Braeburn'/M.26 apple trees with none, low, medium, and high crop load. Harvest was 181 DAFB. having a markedly lower photochemical yield and ETR than the cropping trees but the low-cropping trees also had a lower photochemical yield and ETR than the high- and medium-cropping trees (Fig. 6A and B). The low photochemical yield and ETR of the noncropping trees at 97 DAFB was caused predominantly by a higher percentage of the PSII reaction center pool being closed (i.e.,
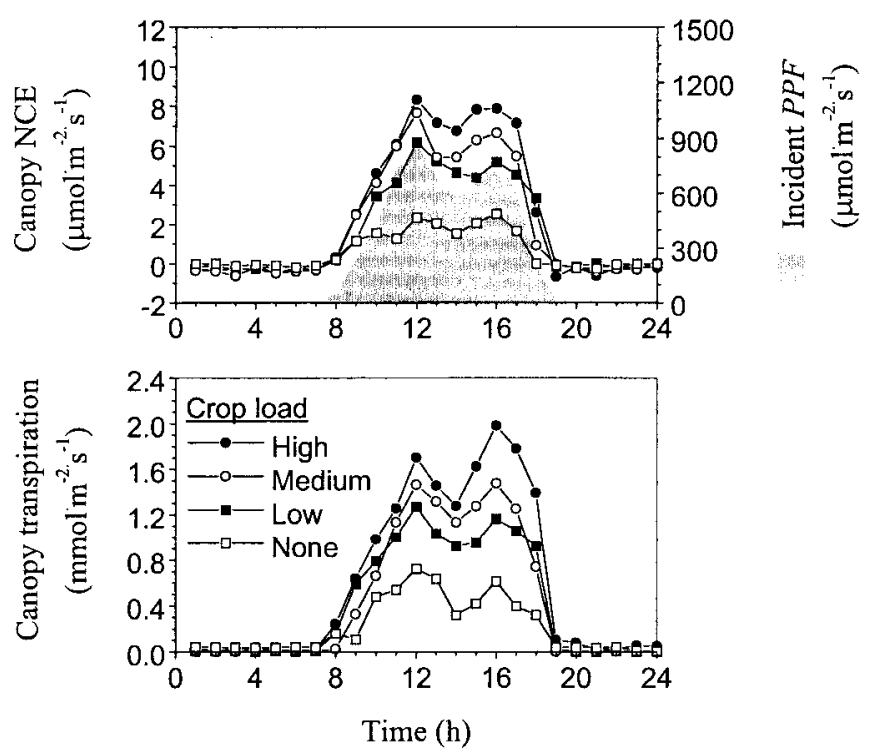

Fig. 3. Diurnal changes of whole-canopy net carbon exchange (NCE) and transpiration per unit area of leaf over a 2 -week period $[\approx 165 \mathrm{~d}$ after full bloom (DAFB)] of 5-year-old 'Braeburn'/M.26 apple trees with none, low, medium, and high crop load. Harvest was 181 DAFB. 

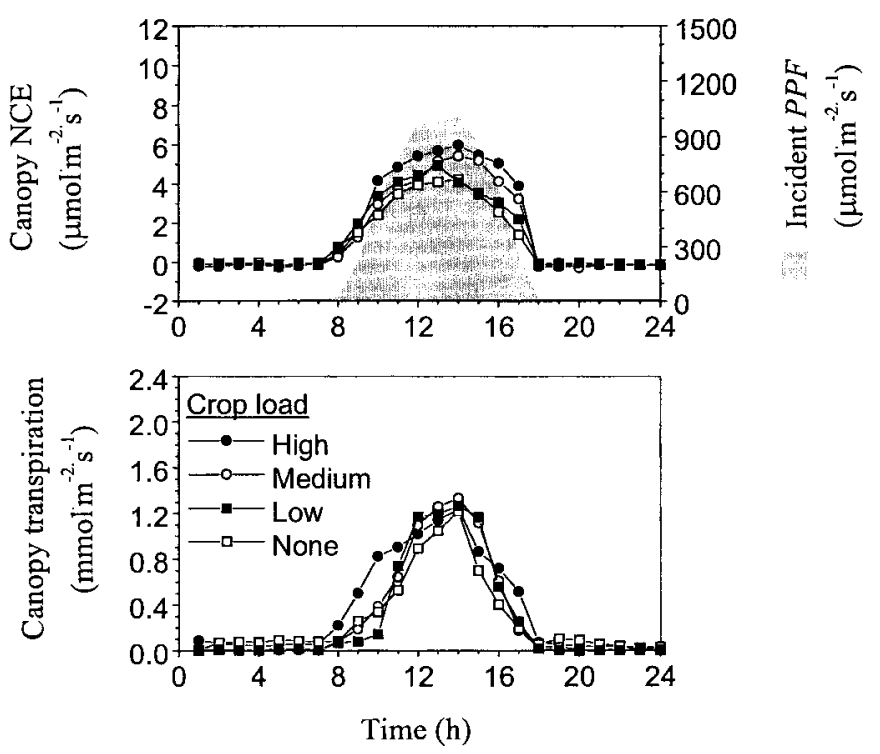

Fig. 4. Diurnal changes of whole-canopy net carbon exchange (NCE) and transpiration per unit area of leaf over a 2 -week period $[\approx 211 \mathrm{~d}$ after full bloom (DAFB)] of 5-year-old 'Braeburn'/M.26 apple trees with none, low, medium, and high crop load. Harvest was 181 DAFB.

lower $\mathrm{q}_{\mathrm{P}}$ ) than in the leaves of the cropping trees (Fig. 6C). At 145 $\mathrm{DAFB}$, however, treatment differences in photochemical yield and ETR were small in spite of marked differences in leaf photosynthesis, although there was an overall decline in ETR. This trend continued after harvest, with both photochemical yield and ETR declining. This was related predominantly to a general increase in thermal dissipation by nonphotochemical quenching (NPQ) rather than to differences in the oxidation state of PSII reaction centers (Fig. 6C and D). Furthermore, across all treatments, at least up to the time of harvest, there was a linear relationship between leaf photosynthesis and photochemical yield (Fig. 7).

\section{Discussion}

Significant differences in whole-canopy leaf area among the various crop load treatments (Table 1) were due to a compensatory response of trees with lower fruit numbers resulting in increased shoot number, shoot length (data not presented) and hence leaf area. Therefore, at the early growth stage, trees with reduced crop loads must have partitioned proportionally larger amounts of photosynthates into these alternative vegetative sinks, which in turn could utilize the extra carbohydrate. While Palmer (1992), Palmer et al. (1997), and Wibbe et al. (1993) found no effect of fruiting on whole-

Table 5. Effect of crop load on starch concentration of bourse shoot leaves of 5-year-old 'Braeburn'/M.26 apple trees 135 days after full bloom. All quadratic effects were nonsignificant.

\begin{tabular}{lccc}
\hline \hline $\begin{array}{l}\text { Crop } \\
\text { load }\end{array}$ & $\begin{array}{c}\text { Starch/leaf dry wt } \\
\left(\mathrm{mg} \cdot \mathrm{g}^{-1}\right)\end{array}$ & $\begin{array}{c}\text { Leaf mass/leaf area } \\
\left(\mathrm{mg} \cdot \mathrm{cm}^{-2}\right)\end{array}$ & $\begin{array}{c}\text { Starch/leaf area } \\
\left(\mathrm{mg} \cdot \mathrm{cm}^{-2}\right)\end{array}$ \\
\hline High & 19 & 10.3 & 0.20 \\
Medium & 41 & 11.0 & 0.45 \\
Low & 67 & 11.7 & 0.78 \\
None & 80 & 12.5 & 1.01 \\
LSD $_{(0.05)}$ & 17.4 & 0.86 & 0.24 \\
Linear trend & $* * *$ & $* * *$ & $* * *$ \\
${ }_{* * *}^{*}$ Significant & & & \\
\hline
\end{tabular}

\footnotetext{
*** Significant at $P \leq 0.001$.
}

canopy leaf area, Lenz (1986) reported significantly greater leaf areas on nonfruiting than fruiting trees, confirming the present findings. Whole-canopy leaf areas corresponded well to daily mean percent tree light interception $\left(r^{2}=0.90\right.$, data not presented $)$ as was shown previously by Wünsche et al. (1996).

Fruit maturity showed a clear response to crop load with advanced maturity on the low-cropping trees. Similar effects of crop load on fruit maturity of 'Cox's Orange Pippin' and 'Braeburn' apples were noted by Sharples (1968) and Palmer et al. (1997), respectively. The underlying principles for the increase in fruit firmness with decreasing crop load is not well understood but could be related to the increase of soluble solids and dry matter. An increase in fruit firmness with lower crop loads has also been reported by Opara et al. (1997).

The downregulating effect of low and no crop load on leaf photosynthesis in apple has often been observed in field studies (Avery, 1975; Kennedy and Fujii, 1985; Monselise and Lenz, 1980a; Palmer, 1992), and the present study is in good agreement with these findings (Table 3). The magnitude of differences in leaf photosynthesis among the crop load treatments was, however, much greater than that reported previously. Palmer et al. (1997) in New Zealand, using the same block of 'Braeburn'/M.26 trees in the 1993-94 growing season, reported similar crop load effects on leaf photosynthesis, including the photosynthetic recovery of trees with reduced crop load just before harvest. It is interesting to note that at $201 \mathrm{DAFB}, 20 \mathrm{~d}$ after harvest, leaf photosynthesis remained comparatively high (Table 3 ), presumably due to optimal postharvest growing conditions combined with relatively healthy foliage on all trees. While a sudden drop in leaf photosynthesis immediately after harvest is reported frequently (e.g., Kennedy and Fujii, 1985), Palmer (1992) recorded a substantial increase in leaf photosynthesis of Crispin/ M.27 trees in all flower removal treatments after the fruit had been picked in mid-October. Possible crop load $\times$ rootstock $\times$ scion $\times$ climate interactions of apple may explain the often contradictory results reported in the literature on the response of leaf photosynthesis after harvest. Moreover, the effect of crop load on leaf photosynthesis is very dependent upon time and severity of flower/fruitlet removal, and it seems that the later the thinning occurs, the greater the effect on photosynthesis since proportionally fewer actively growing sinks are available for alternative carbohydrate movement.

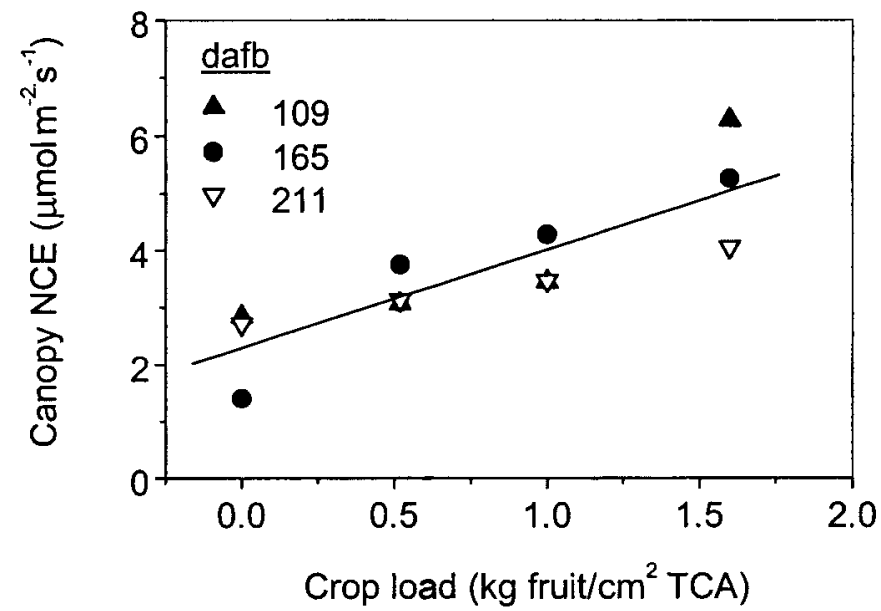

Fig. 5. Effect of crop load on mean whole-canopy net carbon exchange (NCE) per unit area of leaf over 2 weeks at $\approx 109,165$, and 211 days after full bloom of 5year-old 'Braeburn'/M.26 apple trees. Linear regression equation $(\mathrm{n}=12)$ is $\mathrm{NCE}=1.87$ crop load $+2.38, r^{2}=0.70$. 

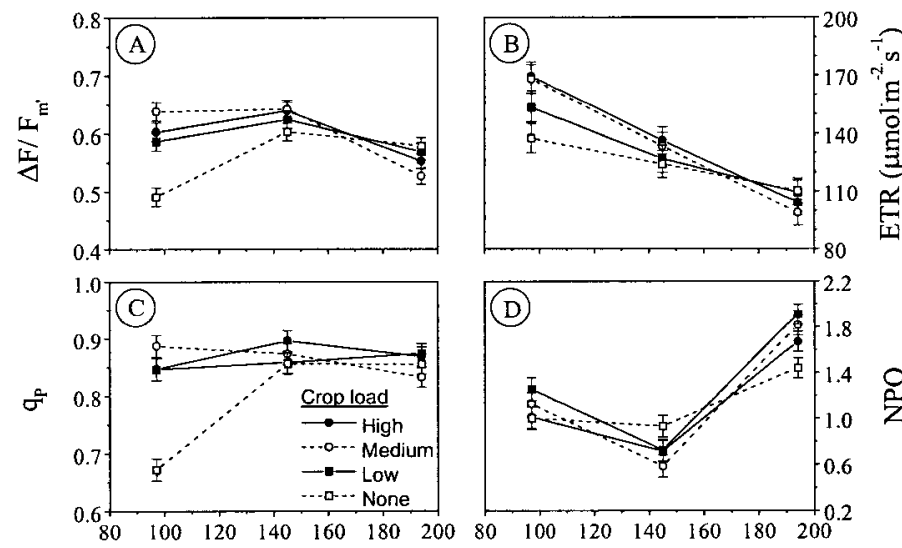

Days after full bloom

Fig. 6. Seasonal changes in (A) photochemical yield $\left(\Delta \mathrm{F} / \mathrm{F}_{\mathrm{m}}{ }^{\prime}\right),(\mathbf{B})$ electron transport rate $(\mathrm{ETR}),(\mathbf{C})$ photochemical quenching $\left(\mathrm{q}_{\mathrm{p}}\right)$, and $(\mathbf{D})$ nonphotochemical quenching (NPQ) of bourse shoot leaves of 5-year-old 'Braeburn'/M.26 apple trees with none, low, medium, and high crop load. Mean photosynthetic photon flux $(P P F)$ at successive measurement times was 440 , 705 , and $675 \mu \mathrm{mol} \cdot \mathrm{m}^{-2} \cdot \mathrm{s}^{-1}$, respectively. Harvest was $181 \mathrm{~d}$ after full bloom. Vertical bars are standard errors of the difference of the means (SEMS).

The substantially increased whole-canopy NCE per unit area of leaf of the high-cropping tree (Table 4) was in spite of up to $40 \%$ less leaf area and $26 \%$ less intercepted light per tree, indicating a high carbohydrate requirement of the actively growing fruit sinks and the limited number of alternative sinks for carbon uptake on trees with reduced or no crop load. Absolute whole-canopy photosynthesis of the lighter-cropping trees may have been limited by the average low incident irradiance within the dense canopy. Daily whole-canopy NCE of $13.8 \mathrm{~g} \mathrm{CO}_{2} / \mathrm{m}^{2}$ leaf area for the high-cropping tree and $5.9 \mathrm{~g} \mathrm{CO}_{2} / \mathrm{m}^{2}$ leaf area for the noncropping tree at $109 \mathrm{DAFB}$ were $\approx 40 \%$ higher than values estimated by Wibbe et al. (1993) for a fruiting and nonfruiting 'Golden Delicious' apple tree at a similar growth stage. The data of Wibbe et al. (1993), indicating that carbon uptake of the fruiting tree largely resembled that of the nonfruiting tree in September just before fruit harvest, could not be confirmed in the present study where whole-canopy NCE per unit area of leaf of the high-fruiting tree exceeded by $\approx 3.5$-fold that of the nonfruiting tree at 165 DAFB. Whole-canopy NCE per unit area of leaf showed a linear response over the range of crop load encountered (Fig. 5). Palmer et al. (1997), however, reported a curvilinear response of leaf assimilation rate to crop load, indicating that care must be taken in extrapolating whole-canopy NCE responses from measurements on a small sample of well-irradiated leaves.

Data on dark respiration suggest that the absolute rate depended on night temperature, confirming results of Butler and Landsberg (1981). The rate differences among the trees were induced by crop load and related strongly to differences in daytime stomatal behavior and photosynthesis. The effect of fruiting on dark respiration is in good agreement with findings of Wibbe et al. (1993) and Butler and Landsberg (1981) who found considerably higher carbon losses on fruiting trees compared to nonfruiting trees. Whole-canopy dark respiration per unit area of leaf of the high-cropping tree at 165 DAFB was $\approx 5$-fold and 2.5fold lower than rates for fruiting apple trees estimated by Butler and Landsberg (1981) and Wibbe et al. (1993), respectively.

Diurnal patterns of whole-canopy NCE and transpiration per unit area of leaf were similar at each measurement time (Figs. 2,
3, and 4), suggesting a strong association between gas-exchange rates and stomatal conductance. Whole-canopy transpiration of $\approx 2 \mathrm{mmol} \cdot \mathrm{m}^{-2} \cdot \mathrm{s}^{-1}$ for the high-cropping tree at $165 \mathrm{DAFB}$ was similar to calculated values by Landsberg et al. (1975) and Butler (1976) of cropping apple trees in middle to late season considering small variations in incident irradiance. The observed effect of crop load on tree water loss is supported by findings of Lenz (1986) who reported higher transpiration rates on fruiting as opposed to nonfruiting trees.

When starch accumulates in leaves, an increase in nonradiative thermal dissipation can occur (Pammenter et al., 1993), indicating a redistribution of energy away from photosynthesis and hence a reduction in photochemical efficiency, that is the interconversion of light to chemical energy by the photochemical apparatus. Consistent with this, at the time of starch sampling at 135 DAFB, there was an indication that photochemical yield was lowest and nonphotochemical quenching was highest in the noncropping trees (Fig. 6A and D). The linear relationship between leaf photosynthesis and photochemical yield confirms that the reduction in photosynthesis in relation to different crop loads was related to a lowered photochemical efficiency (Fig. 7). This relationship has been shown before in maize (Zea mays L.) leaves (Edwards and Baker, 1993). The results also suggest that, as the demand for photosynthate was lowered, the leaves were protected fully by the increased capacity for thermal dissipation (Osmond, 1994). Measurement of the xanthophyll-cycle pigments (Demmig-Adams and Adams, 1996) would have been useful to support this contention.

The significant and positively linear trend between leaf photosynthesis and crop load is in good agreement with a substantially decreasing whole-canopy NCE per unit area of leaf with lower crop load (Tables 3 and 4). As shown for apples previously (Monselise and Lenz, 1980b), treatment differences may be due partly to leaves of fruiting trees having lower gaseous diffusive resistance than nonfruiting trees (Fig. 1). It has been suggested that such stomatal response could be controlled hormonally, e.g., a negatively linear correlation was found between abscisic acid concentration in the xylem sap and leaf conductance(Heckenberger et al., 1996). Differences in stomatal behavior may also be explained by differences in leaf assimilate concentration, in particular starch (Table 5). Accumulation of starch in the leaf chloroplast may induce a feedback regulation of photosynthesis

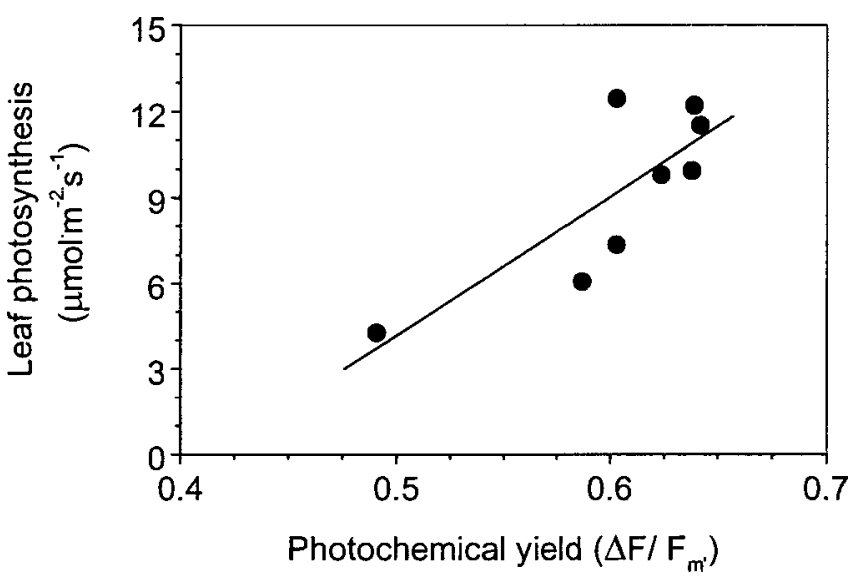

Fig. 7. Relationship between leaf photosynthesis (A) and photochemical yield $\left(\Delta \mathrm{F} / \mathrm{F}_{\mathrm{m}}{ }^{\prime}\right)$ of bourse shoot leaves of 5-year-old 'Braeburn'/M.26 apple trees. Data are limited to that collected before harvest, at 97 and $145 \mathrm{~d}$ after full bloom. Linear regression equation $(\mathrm{n}=8)$ is $\mathrm{A}=48.7 \Delta \mathrm{F} / \mathrm{F}_{\mathrm{m}}-20.2, r^{2}=0.64$. 
presumably brought about by an imbalance between carbon metabolism and absorbed excitation energy and a decline in translocation rates of sucrose and sorbitol (Herold, 1980; Monselise and Lenz, 1980a; Neales and Incoll, 1968).

In summary, crop load affected whole-canopy leaf area, light interception, fruit maturity, leaf photosynthesis, leaf photochemical yield, whole-canopy gas exchange per unit area of leaf, and leaf starch concentration. The effect of crop load on photosynthesis was characterized by 1) a linear downregulation of photosynthesis with reduced crop loads in middle to late season due presumably to an increasingly lower carbohydrate demand; 2) similar photosynthesis across crop loads after harvest, suggesting that other sinks may become increasingly demanding for carbohydrate supply. The diurnal pattern of whole-canopy gas exchange followed closely the diurnal pattern of total incident $P P F$, indicating not only a strong association between gas-exchange rates and gaseous diffusive resistance but also that gas exchange was affected by light irradiance. The differences of whole-canopy dark respiration rate were induced by crop load and related to carbon assimilation during the previous photoperiod before, but not after harvest.

\section{Literature Cited}

Avery, D.J. 1975. Effects of fruits on photosynthetic efficiency, p. 110 112. In: H.C. Pereira (ed.). Climate and the orchard. CAB, Farnham Royal, Slough, U.K.

Butler, D.R. 1976. Estimation of the transpiration rate in an apple orchard from net radiation and vapour pressure deficit measurements. Agr. Meteorol. 16:277-289.

Butler, D.R. and J.J. Landsberg. 1981. Respiration rates of apple trees estimated by $\mathrm{CO}_{2}$-efflux measurements. Plant Cell Environ. 4:153159.

Buwalda, J.G. and G. Noga. 1994. Intra-plant differences in leaf chlorophyll fluorescence parameters in perennial fruiting plants. N.Z. J. Crop Hort. Sci. 22:373-380.

Chow, W.S. 1994. Photoprotection and photoinhibitory damage, p. 151196. In: E.E. Bittar and J. Barber (eds.). Advances in molecular and cell biology. vol 10. Molecular processes of photosynthesis. Jai Press, Inc., Greenwich, U.K.

Demmig-Adams, B. and W.W. Adams, III. 1996. The role of xanthophyll cycle carotenoids in the protection of photosynthesis. Trends Plant Sci. 1:21-26.

Edwards, G.E. and N.R. Baker. 1993. Can CO assimilation in maize leaves be predicted accurately from chlorophyll fluorescence analysis? Photosyn. Res. 37:89-102.

Freeman, G.H. and B.D Bolas. 1956. A method for the rapid determination of leaf areas in the field, p. 104-107. Rpt. East Malling Res. Sta. 1955.

Greer, D.H. 1995. Effect of canopy position on the susceptibility of kiwifruit (Actinidia deliciosa) leaves on vines in an orchard environment to photoinhibition throughout the growing season. Austral. J. Plant Physiol. 22:299-309.

Hansen, P. 1970. ${ }^{14} \mathrm{C}$-studies on apple trees. VI. The influence of the fruit on the photosynthesis of leaves, and the relative photosynthetic yields of fruits and leaves. Physiol. Plant. 23:805-810.

Heckenberger, U., U. Schurr, and E-D. Schulze. 1996. Stomatal response to abscisic acid fed into the xylem of intact Helianthus annuus (L.) plants. J. Expt. Bot. 302:1405-1412.

Heim, G., J.J. Landsberg, R.L. Watson, and P. Brain. 1979. Ecophysiology of apple trees: Dry matter production and partitioning in young 'Golden Delicious' apple trees. J. Appl. Ecol. 16:179-194.

Herold, A. 1980. Regulation of photosynthesis by sink activity-The missing link. New Phytol. 86:131-144.

Kennedy, R.A and J.A. Fujii. 1985. Seasonal and developmental changes in apple photosynthesis: Enhancement effects due to flowering and fruit maturation, p. 27-29. In: A.N. Lakso and F. Lenz (eds.). The regulation of photosynthesis in fruit trees. Proc. N.Y. State Agr. Expt. Sta., Geneva.

Landsberg, J.J., C.L. Beadle, P.V. Biscoe, D.R. Butler, B. Davidson, L.D. Incoll, G.B. James, P.G. Jarvis, P.J. Martin, R.E. Neilson, D.B.B. Powell, E.M. Slack, M.R. Thorpe, N.C. Turner, B. Warrit, and W.R. Watts. 1975. Diurnal energy, water and $\mathrm{CO}_{2}$ exchanges in an apple (Malus pumila) orchard. J. Appl. Ecol. 12:659-684.

Lenz, F. 1986. Fruit effects on transpiration and dry matter production in apples, p. 101-104. In: A.N. Lakso and F. Lenz (eds.). The regulation of photosynthesis in fruit trees. Proc. N.Y. State Agr. Expt. Sta., Geneva.

Maggs, D.H. 1963. The reduction in growth of apple trees brought about by fruiting. J. Hort. Sci. 39:85-94.

Monselise, S.P. and F. Lenz. 1980a. Effect of fruit load on photosynthetic rates of budded apple trees. Gartenbauwiss 45:220-224.

Monselise, S.P. and F. Lenz. 1980b. Effects of fruit load on stomatal resistance, specific leaf weight, and water content of apple leaves. Gartenbauwiss 45:188-191.

Neales, T.F. and L.D. Incoll. 1968. The control of leaf photosynthesis rate by the level of assimilate concentration in the leaf: A review of the hypothesis. Bot. Rev. 43:107-125.

Opara, L.U., C.J. Studman, and N.H. Banks. 1997. Physico-mechanical properties of 'Gala' apples and stem-end splitting as influenced by orchard management practices and harvest data. J. Agr. Eng. Res. 68:139-146.

Osmond, C.B. 1994. What is photoinhibition? Some insights from comparisons of shade and sun plants, p. 1-24. In: N.R. Baker and J.R. Bowyer (eds.). Photoinhibition of photosynthesis from molecular mechanisms to the field. Bios Scientific Publishers, Oxford, U.K.

Palmer, J.W. 1986. Seasonal variation of light saturated photosynthetic rate of 'Golden Delicious' apple leaves as influenced by leaf type and crop load, p. 30-33. In: A.N. Lakso and F. Lenz (eds.). The regulation of photosynthesis in fruit trees. Proc. N.Y. State Agr. Expt. Sta., Geneva.

Palmer, J.W. 1987. A simple, robust light meter for measuring light in orchards. J. Hort. Sci. 62:1-4.

Palmer, J.W. 1992. Effects of varying crop load on photosynthesis, dry matter production and partitioning of Crispin/M.27 apple trees. Tree Physiol. 11:19-33.

Palmer, J.W., R. Giuliani, and H.M. Adams. 1997. Effect of crop load on fruiting and leaf photosynthesis of 'Braeburn'/M.26 apple trees. Tree Physiol. 17:741-746.

Pammenter, N.W., F. Loreto, and T.D. Sharkey. 1993. End product feedback effects on photosynthetic electron transport. Photosyn. Res. 35:5-14.

Sharples, R.O. 1968. Fruit thinning effects on the development and storage quality of 'Cox's Orange Pippin' apple fruits. J. Hort. Sci. 43:359-371.

Smith, G.S., C.J. Clark, and H.L. Boldingh. 1992. Seasonal accumulation of starch by components of the kiwifruit vine. Ann. Bot. 70:19-25.

Van Kooten, O. and J.F.H. Snel. 1990. The use of chlorophyll fluorescence nomenclature in plant stress studies. Photosyn. Res. 25:147-150. Wibbe, M.L., M.M. Blanke, and F. Lenz. 1993. Effect of fruiting on carbon budgets of apple tree canopies. Trees 8:56-60.

Wünsche, J.N., A.N. Lakso, and T.L. Robinson. 1995. Comparison of four methods for estimating total light interception by apple trees of varying forms. HortScience 30:272-276.

Wünsche, J.N., A.N. Lakso, T.L. Robinson, F. Lenz, and S.S. Denning. 1996. The bases of productivity in apple production systems: The role of light interception by different shoot types. J. Amer. Soc. Hort. Sci. 121:886-893.

Wünsche, J.N. and J.W. Palmer. 1997. Portable through-flow cuvette system for measuring whole-canopy gas exchange of apple trees in the field. HortScience 32:653-658.

Wünsche, J.N. and J.W. Palmer. 1998. Comparison of non-destructive methods for estimating leaf area of apple tree canopies. Acta Hort. 243:175-184. 